Annals of International Medical and Dental Research

E-ISSN: 2395-2822 | P-ISSN: 2395-2814

Vol-8, Issue-2 | March-April 2022

DOI: 10.53339/aimdr.2022.8.2.13

Page no- 91-98 | Section- Research Article (Surgery)

\title{
To Evaluate the Feasibility of Flip Technique in Dissection of Gall Bladder from the Liver Bed in Laparoscopic Cholecystectomy and Its Comparison with Standard Laparoscopic Cholecystectomy
}

\author{
Sanjeev Gupta ${ }^{1}$ P.K. Pandove ${ }^{2}$, Vikram Garg ${ }^{3 *}$, Samidha Jindal', Karamjot Sandhu ${ }^{5}$
}

\begin{abstract}
${ }^{1}$ Associate Professor, Department of General Surgery, Rajindra Hospital, Patiala, Punjab, India.

Email: drsanjivms@gmail.com,

Orcid ID: 0000-0003-2123-3201

2Professor, Department of General Surgery, Rajindra Hospital, Patiala, Punjab, India,

Email: drpandovepk@yahoo.co.in,

Orcid ID: 0000-0002-8836-8154

3Senior Resident, Department of General Surgery, Rajindra Hospital, Patiala, Punjab, India.

Email: garg.vikram2668@gmail.com,

Orcid ID: 0000-0001-5800-1514

4Senior Resident, Department of Pathology, Rajindra Hospital, Patiala, Punjeb, India.

Email: samidha.jindal28@gmail.com

Orcid ID: 0000-0002-6934-9572

5Senior Resident, Department of General Surgery, Rajindra Hospital, Patiala, Punjab, India.

Email: sandhukss@gmail.com

Orcid ID: 0000-0003-0320-4562
\end{abstract}

*Corresponding author

Received: 30 April 2021

Revised: 04 June 2021

Accepted: 16 June 2021

Published: 18 February 2022

\begin{abstract}
Background: Laparascopic cholecystectomy is one of the commonly performed surgery and is the procedure of choice for gall bladder disease. Time to time advancements are being made in this procedure to ease this surgery and also decrease its complication rate. And with the same purpose, a special technique named as "Flip Technique" has been introduced in which, in order to make the dissection of gall bladder easier near the fundus, the gall bladder is flipped over the liver surface after initial dissection of the gall bladder from the liver bed. The study to find out the feasibility of this flip technique of gall bladder removal in laparoscopic cholecystectomy was done in 100 patients admitted in department of general surgery, Govt Medical College and Rajindra Hospital, Patiala. Aim: This study aims to evaluate the feasibility of Flip technique for dissection of gall bladder from the liver bed in laparoscopic cholecystectomy with regard to operative time, intraoperative bleeding, bile duct injury, liver bed injury, injury to gall bladder wall, duration of hospital stay and mortality (if any). Methods: The present study was prospective, observational and comparative trial and was conducted on 100 patients of either sex diagnosed as case of GBD and planned for laparoscopic cholecystectomy, admitted in surgical ward of Rajindra Hospital, Patiala. Results: Latrogenic GB rupture occurred in $2 \%$ of patients in group A (cases) and $12 \%$ of patients in group B (control). The difference was statistically significant ( $p$ value 0.05 ). Site of rupture in group $\mathrm{A}$ is fundus of gall bladder in $2 \%$ of patients and none of gall bladder rupture is seen at body or Hartman's pouch. In group B gall bladder rupture was found at fundus in $6 \%$ of patients, at body in $4 \%$ patients and Hartman's pouch in $2 \%$ of patients. Conclusions: The use of Flip technique was more advantageous as compared to standard method of gall bladder dissection from liver bed in laparoscopic cholecystectomy with the mean duration of surgery being shorter in Flip technique.
\end{abstract}

Keywords:- Gall Bladder, Laparoscopic Cholecystectomy.

\section{INTRODUCTION}

Gall bladder stones affect a significant percentage of population throughout the world and they remain major cause of abdominal morbidity.[1] In spite of the detailed knowledge on anatomy and other developments, no surgical intervention was done till Langenbach 
Annals of International Medical and Dental Research

E-ISSN: 2395-2822 | P-ISSN: 2395-2814

Vol-8, Issue-2 | March-April 2022

DOI: 10.53339/aimdr.2022.8.2.13

Page no- 91-98 | Section- Research Article (Surgery)

of Berlin who did the first cholecystectomy in 1882 on a 43 year old male. The patient recovered and was discharged from the hospital after 8 weeks.[2] Since that day gradually, gall bladder surgery progressed from a long subcostal incision to mini laparotomy in 1970-1980.[]]

The gall bladder is a hollow organ that sits in a shallow depression below the right lobe of the liver. In adults, the gall bladder measures approximately 7 to 10 centimetres (2.8 to 3.9 inches) in length and 4 centimetres (1.6 inches) in diameter when fully distended. The gall bladder has a capacity of about 50 millilitres (1.8 imperial fluid ounces).[4]

The gall bladder is shaped like a pear, with its tip opening into the cystic duct. The gall bladder is divided into three sections: the fundus, body, and neck. The fundus is the rounded base, angled so that it faces the abdominal wall. The body lies in a depression in the surface of the lower liver. The neck tapers and is continuous with the cystic duct, part of the biliary tree. The gall bladder fossa, against which the fundus and body of the gall bladder lie, is found beneath the junction of hepatic segments IV B and V. The cystic duct unites with the common hepatic duct (CHD) to become the common bile duct (CBD). At the junction of the neck of the gall bladder and the cystic duct, there is an out-pouching of the gall bladder wall forming a mucosal fold known as "Hartmann's pouch" where gall stones generally get impacted. [5]

Gallstone disease is often thought to be a major affliction in modern society.[6] However, gallstones must have been known to humans for many years, since they have been found in the gall bladders of Egyptian mummies dating back to 1000 BC. [7,8] This disease is however, a worldwide medical problem, even though there are geographical variations in gallstone prevalence. $[9,10,11,12,13,14,15] \quad$ Gallstones are becoming increasingly common; they are seen in all age groups, but the incidence increases with age; [16] and about a quarter of women over 60 years will develop them.[17] In most cases they do not cause symptoms, and only $10 \%$ and $20 \%$ will eventually become symptomatic within 5 years and 20 years of diagnosis.[18,19] Thus the average risk of developing symptomatic disease is low, and approaches 2.0-2.6\% / year. [19]

\section{MATERIAL AND METHODS}

The present study was a prospective, observational and comparative trial which was conducted on 100 patients of either sex diagnosed as case of Gall Bladder Disease and planned for laparoscopic cholecystectomy, who fulfill the inclusion criteria, admitted in surgical ward of Rajindra Hospital, Patiala.

\section{Inclusion Criteria}

1. Adult patients ( $>18$ years of age).

2. Patients of either sex.

3. Patients ready to give consent for the trial.

\section{Exclusion Criteria}

1. Patients with coagulation disorder.

2. Pregnancy.

3. Patient unfit for general anaesthesia.

4. Patients who refused to give consent for the trial.

All the patients were divided into two groups after taking an informed consent: 
Annals of International Medical and Dental Research

E-ISSN: 2395-2822 | P-ISSN: 2395-2814

Vol-8, Issue-2 | March-April 2022

DOI: 10.53339/aimdr.2022.8.2.13

Page no- 91-98 | Section- Research Article (Surgery)

Group A: Patients who underwent liver bed dissection using Flip technique in laparoscopic cholecystectomy .

Group B: Patients who underwent liver bed dissection in laparoscopic cholecystectomy with standard technique.

In all cases relevant history, general physical examination and investigations were done to confirm diagnosis and assess surgical status of patient. An informed consent was also taken.

\section{Procedure}

After overnight fasting, all patients were given one dose of antibiotic thirty minutes before surgery along with pre-medication. All were operated under general anaesthesia and 4 port technique was used.

Two $10 \mathrm{~mm}$ ports and two $5 \mathrm{~mm}$ ports were used- one $10 \mathrm{~mm}$ port in the umbilical and epigastric region each, one $5 \mathrm{~mm}$ port in the right hypochondrium and right lumbar each. Pneumoperitoneum was created. After the abdominal survey, the patient was placed in head up position with the patient tilted to the left. Gall bladder was grasped from the infundibulum through a $5 \mathrm{~mm}$ port and retracted cephalad for linear retraction and to open up the Calot's triangle for dissection. Posterior dissection of Calot's triangle was done, once posterior dissection is complete, anterior dissection of Calot's triangle was done. After complete skeletonization of Calot's triangle, the junction of cystic duct and gall bladder was defined. Two proximal and one distal titanium clips were applied on cystic duct and artery and both of them are cut inbetween the clips. The gall bladder was removed from liver bed by Flip technique in which as the gall bladder dissection approaches fundus and more than two third of gall bladder was dissected from liver bed, the assistant was asked to leave the traction from the gall bladder fundus (i.e. anterior axillary line port) while the surgeon holds the dissected surface of gall bladder with a grasper and flipped it above the liver. The traction so caused at lateral and medial peritoneal folds of gall bladder made dissection of gall bladder quite easy using the electrocautery hook. The last bit of the attachment between the fundus and liver was preserved till the end which helps in providing traction to liver using the left hand instrument of the surgeon. This aids in accurate dissection of the gall bladder from liver bed.

The gall bladder was extracted through the epigastric port. Operative time from onset of procedure (i.e. time since incision was given) to closure of wound was noted. Intraoperative findings like operative time and intraoperative complications like intraoperative bleeding, bile duct injury, liver bed injury, injury to gall bladder wall and injury to any other organ were recorded. Post-operative hospital stay was noted.

The findings noted down for the patients in two sub groups were compared and results were evaluated at the end of study.

\section{RESULTS}

The mean duration of surgery in Group A was $52.46 \pm 18.64$, ranging from 25 to 118 minutes. The mean duration of surgery in group B was $54.90 \pm 19.25$, ranging from 25 to 110 minutes. The difference was statistically non significant ( $\mathrm{p}$ value 0.521 ). 
Annals of International Medical and Dental Research E-ISSN: 2395-2822 | P-ISSN: 2395-2814

Vol-8, Issue-2 | March-April 2022

DOI: 10.53339/aimdr.2022.8.2.13

Page no- 91-98 | Section- Research Article (Surgery)

The iatrogenic GB rupture occurred in 1 out of $50(2 \%)$ patients in group A and in 6 out of 50 $(12 \%)$ patients in group $B$. The difference was statistically significant ( $p$ value 0.05 ).

The site of rupture in group A is fundus of gall bladder i.e. in 1 out of $50(2 \%)$ patient and none of gall bladder rupture is seen at body or Hartman's pouch. In group B, gall bladder rupture was found at fundus in 3 out of 50
(6\%) patients, at body in 2 out of $50(4 \%)$ patients and Hartman's pouch in 1 out of 50 ( $2 \%)$ patients.

The mean duration of postoperative hospital stay remains same in two groups i.e. $2.42 \pm 0.81$ in group A and $2.42 \pm 0.92$ in group B. P value came out to be 0.346 which was statistically non significant.

Table 1: Incidence Of Iatrogenic Gb Rupture In Two Groups

\begin{tabular}{|l|l|l|l|l|}
\hline \multirow{2}{*}{$\begin{array}{l}\text { Iatrogenic } \\
\text { GB Rupture }\end{array}$} & Group A & Group B & \% age \\
\cline { 2 - 5 } & No. & \%age & No. & \% \\
\hline Present & 1 & $2 \%$ & 6 & $12 \%$ \\
\hline Absent & 49 & $98 \%$ & 44 & $88 \%$ \\
\hline Total & 50 & $100 \%$ & 50 & $100 \%$ \\
\hline p value & 0.05 & & \\
\hline Significance & Significant & & \\
\hline
\end{tabular}

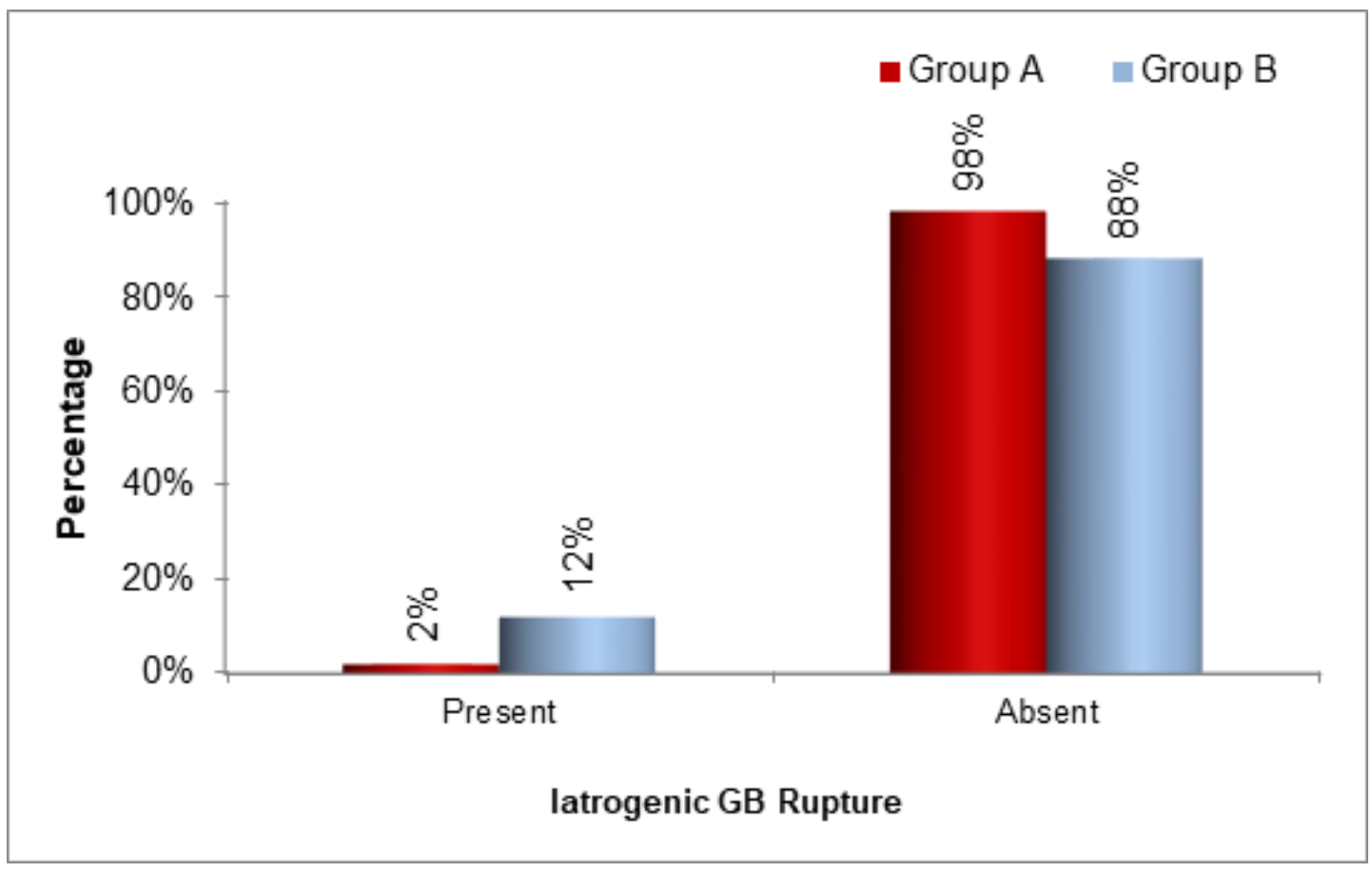


Annals of International Medical and Dental Research E-ISSN: 2395-2822 | P-ISSN: 2395-2814

Vol-8, Issue-2 | March-April 2022

DOI: 10.53339/aimdr.2022.8.2.13

Page no- 91-98 | Section- Research Article (Surgery)
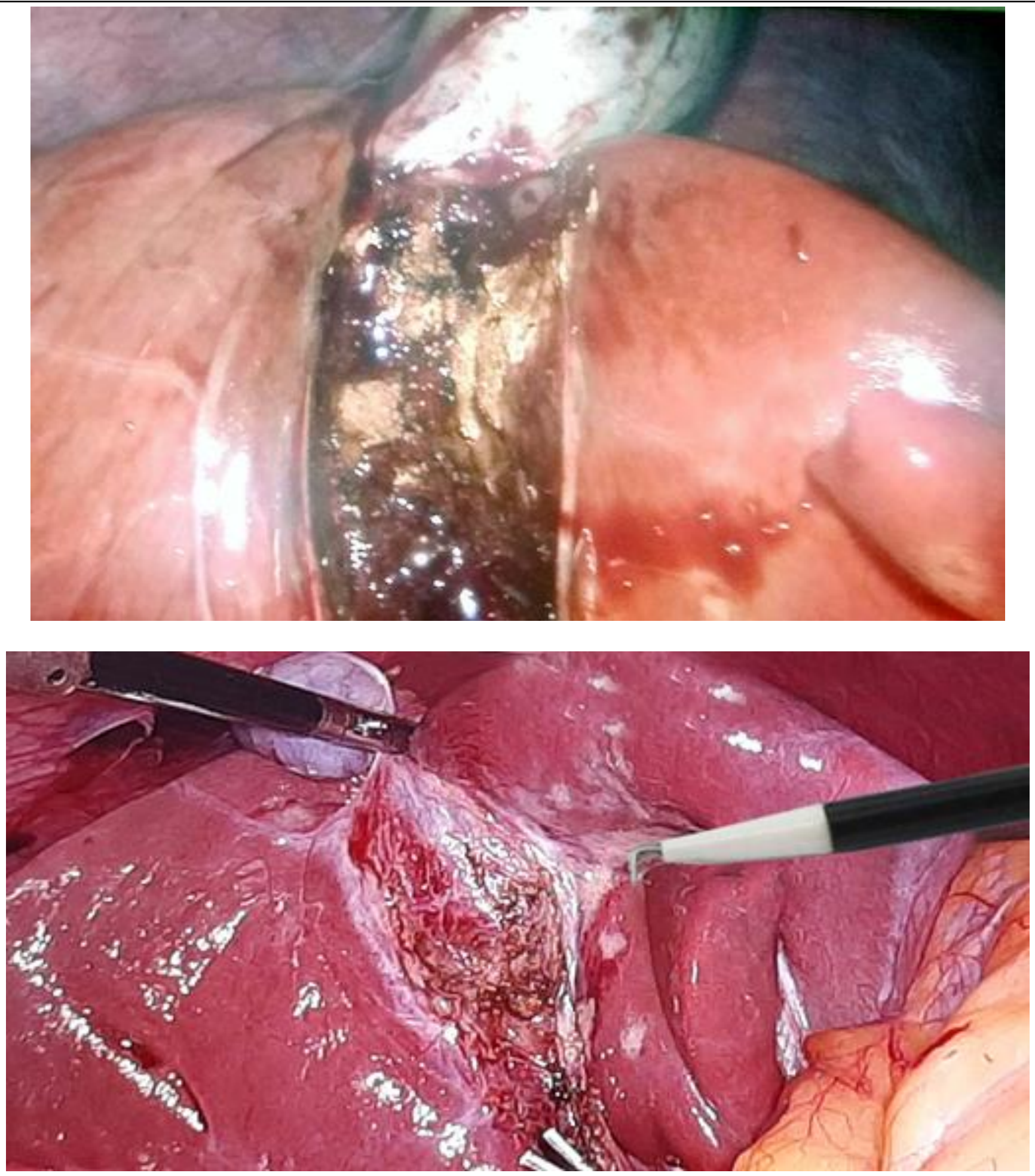

Gall Bladder Being 'Flipped' Above The Liver 
Annals of International Medical and Dental Research

E-ISSN: 2395-2822 | P-ISSN: 2395-2814

Vol-8, Issue-2 | March-April 2022

DOI: 10.53339/aimdr.2022.8.2.13

Page no- 91-98 | Section- Research Article (Surgery)

\section{DISCUSSION}

Present study was conducted "to evaluate the feasibility of Flip technique in dissection of gall bladder from the liver bed in laparoscopic cholecystectomy and its comparison with standard laparoscopic cholecystectomy" included 100 patients divided into two groups. The current study was performed to determine the advantages of Flip technique for dissection of gall bladder from liver bed during laparoscopic cholecystectomy.[20]

Till now, no or little stress has been given for ease of proper dissection of gall bladder from liver bed. The precise steps for the removal of gall bladder from the gall bladder fossa/bed are not well standardized resulting in bleeding, bile and stone spillage which not only contaminates the peritoneal cavity but also makes the extraction of gall bladder challenging due to continuous dripping of bile and necessitates additional use of an endobag. [21,22]

\section{Iatrogenic GB Rupture}

Keeping all the statistics i.e. preoperative preparation and gall bladder wall thickness (2$3 \mathrm{~mm}$ ) similar, the incidence of gall bladder perforation was found to be significantly higher in group B than group A because of non standardization of dissection of gall bladder from liver bed. Intraoperative gall bladder perforation occurs in $13 \%-50 \%$ of patients who undergo laparoscopic cholecystectomy, and in $10 \%-40 \%$ of these patients, bile leakage and stone spillage are present.[23] Laceration due to grasper traction and untrained assistance is the most common cause of gall bladder rupture during laparoscopic cholecystectomy.[24]
Perforation of gall bladder results in spillage of bile or stones or both into the peritoneal cavity. The duration of surgery in these cases is more because time is wasted in retrieving the stones from the peritoneal cavity and in doing repeated suction and irrigation of the peritoneal cavity in cases of bile spillage and lost stones due to gall bladder perforation.

\section{$\underline{\text { Site of Gall Bladder Rupture }}$}

The most common site of rupture is fundus of gall bladder followed by body and Hartman's pouch of gall bladder which is comparable and similar to other study.

\section{Gall Bladder Bed Haemorrhage}

Gall bladder bed haemorrhage was seen in 1 out of $645(0.3 \%)$ patients in study done by Sharma et al[22] (2017) but no comparsion was done in their study. In our study, the incidence of intraoperative Gall bladder bed haemorrhage requiring electrocautery application or packing during dissection of gall bladder from liver bed was compared. GB bed haemorrhage occurred in 1 out $50(2 \%)$ patients in group A and in 3 out of $50(6 \%)$ patients in group B.

\section{Liver Injury}

In study by Sharma et al (2017),[22] Incidence of intraoperative liver injury during dissection of gall bladder from liver bed was seen to be $0.15 \%$. In our study, liver injury was seen to occur in $0(0 \%)$ in group A and $3(6 \%)$ in group $\mathrm{B}$ which was similar and comparable to similar study.

Cystic artery haemorrhage, CBD injury, duodenal injury, other organ injury or any 
Annals of International Medical and Dental Research E-ISSN: 2395-2822 | P-ISSN: 2395-2814

Vol-8, Issue-2 | March-April 2022

DOI: 10.53339/aimdr.2022.8.2.13

Page no- 91-98 | Section- Research Article (Surgery)

other post operative complication were not seen in two groups

\section{Retrieval of Spilled Bile \& GB Stones}

In our study, extensive prompt retrieval of the bile and stone spillage was done along with abundant irrigation from peritoneal cavity in 7 out of 50 patients $(14.00 \%)$ in both the groups i.e. 1 out of 50 patients in group $A$ and 6 out of 50 patients in group $B$.

\section{CONCLUSIONS}

The following conclusions were drawn from the study:

1. The use of Flip technique was more advantageous as compared to standard method of gall bladder dissection from liver bed in laparoscopic cholecystectomy.

2. The mean duration of surgery was shorter when Flip technique was used as compared

\section{REFERENCES}

1. Barbara L, Sama C, Morselli Labate AM, Taroni F, Rusticali AG, Festi D, et al. A population study on the prevalence of gallstone disease: the Sirmione Study. Hepatology. 1987;7(5):913-7. doi: 10.1002/hep.1840070520.

2. Li J, Long $X$, Fang $X$, et al. SARS-CoV-2 positivity in a discharged COVID-19 patient: a case report. Clin Microbiol Infect. 2020;26(8):1115-1117. doi:10.1016/j.cmi.2020.04.032

3. Portincasa P, Di Ciaula A, de Bari O, Garruti G, Palmieri VO, Wang DQ. Management of gallstones and its related complications. Expert Rev Gastroenterol Hepatol. 2016;10(1):93-112. doi: 10.1586/17474124.2016.1109445.

4. Vezina WC, Paradis RL, Grace DM, Zimmer RA, Lamont DD, Rycroft KM, et al. Increased volume and decreased emptying of the gallbladder in large (morbidly obese, tall normal, and muscular normal) to standard method of gall bladder dissection from liver bed because of standardization of dissection.

3. Flip technique avoids tug of war like situation which is usually seen in standard method of gall bladder dissection from liver bed.

4. The incidence of iatrogenic GB rupture was fewer in Flip technique group as compared to control group.

5. The incidence of iatrogenic GB bed haemorrhage and liver injury was fewer in Flip technique group as compared to control group.

This study itself has a limitation of small sample size so larger randomized trials may identify more subtle advantages of one method over another.

people. Gastroenterology. 1990;98(4):1000-7. doi: 10.1016/0016-5085(90)90025-v.

5. Nagral S. Anatomy relevant to cholecystectomy. J Minim Access Surg. 2005;1(2):53-58. doi:10.4103/0972-9941.16527

6. Njeze GE. Gallstones. Niger J Surg. 2013;19(2):49-55. doi:10.4103/1117-6806.119236

7. Shojaiefard A, Esmaeilzadeh M, Ghafouri A, Mehrabi A. Various techniques for the surgical treatment of common bile duct stones: a meta review. Gastroenterol Res Pract. 2009;2009:840208. doi: $10.1155 / 2009 / 840208$.

8. Gordon-Taylor G. On gallstones and their sufferers. Br J Surg. 1937;25(98):241-51.

9. Hadidy S, Turki J, Misri HT. Cholelithiasis in the Syrian population. A prospective study of 189 patients. Am J Surg. 1987;153(4):392-3. doi: 10.1016/0002-9610(87)90584-8.

10. Sampliner RE, Bennett PH, Comess LJ, Rose FA, Burch TA. Gallbladder disease in pima indians. 
Annals of International Medical and Dental Research E-ISSN: 2395-2822 | P-ISSN: 2395-2814

Vol-8, Issue-2 | March-April 2022

DOI: 10.53339/aimdr.2022.8.2.13

Page no- 91-98 | Section- Research Article (Surgery)

Demonstration of high prevalence and early onset by cholecystography. $\mathrm{N}$ Engl J Med. 1970;283(25):1358-64. doi: 10.1056/NEJM197012172832502.

11. Acalovschi M. Cholesterol gallstones: from epidemiology to prevention. Postgrad Med J. 2001;77(906):221-229. doi:10.1136/pmj.77.906.221

12. Biss K, Ho KJ, Mikkelson B, Lewis L, Taylor CB. Some unique biologic characteristics of the Masai of East Africa. N Engl J Med. 1971;284(13):694-9. doi: 10.1056/NEJM197104012841304.

13. Onuigbo WI. A biopsy study of gallstones in Nigerian igbos. Digestion. 1977;15(4):353-5. doi: 10.1159/000198022.

14. Halldestam I, Enell EL, Kullman E, Borch K. Development of symptoms and complications in individuals with asymptomatic gallstones. Br J Surg. 2004;91(6):734-8. doi: 10.1002/bjs.4547.

15. Rahman GA. Cholelithiasis and cholecystitis: changing prevalence in an African community. J Natl Med Assoc. 2005;97(11):1534-1538.

16. Stinton LM, Shaffer EA. Epidemiology of gallbladder disease: cholelithiasis and cancer. Gut Liver. 2012;6(2):172-187. doi:10.5009/gnl.2012.6.2.172

17. Dray X, Joly F, Reijasse D, Attar A, Alves A, Panis Y, et al. Incidence, risk factors, and complications of cholelithiasis in patients with home parenteral nutrition. J Am Coll Surg. 2007;204(1):13-21. doi: 10.1016/j.jamcollsurg.2006.09.008.

18. Thistle JL, Cleary PA, Lachin JM, Tyor MP, Hersh T. The natural history of cholelithiasis: the National Cooperative Gallstone Study. Ann Intern Med. 1984;101(2):171-5. doi: 10.7326/0003-4819-101-2-171.
19. Friedman GD, Raviola CA, Fireman B. Prognosis of gallstones with mild or no symptoms: 25 years of follow-up in a health maintenance organization. J Clin Epidemiol. 1989;42(2):127-36. doi: 10.1016/08954356(89)90086-3.

20. Power C, Maguire D, McAnena OJ, Calleary J. Use of the ultrasonic dissecting scalpel in laparoscopic cholecystectomy. Surg Endosc. 2000;14(11):1070-3. doi: $10.1007 / \mathrm{s} 004640000034$.

21. Zubair M, Habib L, Mirza MR, Channa MA, Yousuf M. Iatrogenic gall bladder perforations in laparoscopic cholecystectomy: an audit of 200 cases. Mymensingh Med J. 2010;19(3):422-6.

22. Sharma M, Vindal A, Lal P. Gall bladder flip technique in laparoscopic cholecystectomy. J Minim Access Surg. 2017;13(4):318-320. doi: 10.4103/jmas.JMAS_84_17.

23. Memon MA, Deeik RK, Maffi TR, Fitzgibbons RJ Jr. The outcome of unretrieved gallstones in the peritoneal cavity during laparoscopic cholecystectomy. A prospective analysis. Surg Endosc. 1999;13(9):848-57. doi: $10.1007 / \mathrm{s} 004649901118$.

24. Hui TT, Giurgiu DI, Margulies DR, Takagi S, Iida A, Phillips EH. Iatrogenic gallbladder perforation during laparoscopic cholecystectomy: etiology and sequelae. Am Surg. 1999;65(10): 944-8.

Source of Support: Nil, Conflict of Interest: None declared 